\title{
Experimental Study of Hardened Young's Modulus for 3D Printed Mortar
}

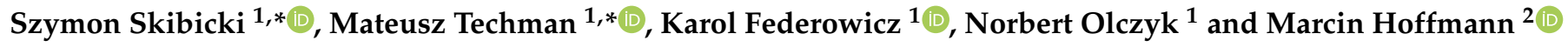 \\ 1 Faculty of Civil and Environmental Engineering, West Pomeranian University of Technology in Szczecin, \\ al. Piastów 50a, 70-311 Szczecin, Poland; karol.federowicz@zut.edu.pl (K.F.); \\ norbert.olczyk@zut.edu.pl (N.O.) \\ 2 Faculty of Mechanical Engineering and Mechatronics, West Pomeranian University of Technology in Szczecin, \\ al. Piastów 19, 70-310 Szczecin, Poland; marcin.hoffmann@zut.edu.pl \\ * Correspondence: szymon.skibicki@zut.edu.pl (S.S.); mtechman@zut.edu.pl (M.T.)
}

check for updates

Citation: Skibicki, S.; Techman, M.; Federowicz, K.; Olczyk, N.; Hoffmann, M. Experimental Study of Hardened Young's Modulus for 3D Printed Mortar. Materials 2021, 14, 7643. https://doi.org/10.3390/ ma14247643

Academic Editor: Gabriele Milani

Received: 29 November 2021 Accepted: 8 December 2021 Published: 11 December 2021

Publisher's Note: MDPI stays neutral with regard to jurisdictional claims in published maps and institutional affiliations.

Copyright: (c) 2021 by the authors. Licensee MDPI, Basel, Switzerland. This article is an open access article distributed under the terms and conditions of the Creative Commons Attribution (CC BY) license (https:/ / creativecommons.org/licenses/by/ $4.0 /)$.

\begin{abstract}
Few studies have focused on determining the Young's modulus of 3D printed structures. This study presents the results of experimental investigations of Young's modulus of a 3D printed mortar. Specimens were prepared in four different ways to investigate possible application of different methods for 3D printed structures. Study determines the influence of the number of layers on mechanical properties of printed samples. Results have shown a strong statistical correlation between the number of layers and value of Young's modulus. The compressive strength and Young's modulus reduction compared to standard cylindrical sample were up to $43.1 \%$ and $19.8 \%$, respectively. Results of the study shed light on the differences between the current standard specimen used for determination of Young's modulus and the specimen prepared by 3D printing. The community should discuss the problem of standardization of test methods in view of visible differences between different types of specimens.
\end{abstract}

Keywords: 3D mortar; 3D concrete; Young's modulus; elastic modulus; harden property

\section{Introduction}

The 3D printing of cementitious materials is one of the fastest growing branches of industry in recent years. A significant number of studies have been conducted on the properties of the fresh mix used in the process of printing. The focus is on being able to print bigger structures in a shorter time [1-9]. However, the long-term material properties of hardened cementitious composite should also be considered [10-15]. Due to multilayer characteristic of the printed structure, it is necessary to determine properties such as compressive strength, flexural strength, or modulus of elasticity to fully understand the behaviour of the structure as a whole. Those parameters are essential for proper structural designing with 3D printing.

The majority of studies on hardened properties have focused on compressive strength and flexural strength in regard to the anisotropic behaviour of printed elements. Anisotropy is caused by the layered structure of the elements [16-21]. Additionally, a significant number of published research articles have determined the properties on standard samples, proving the negative impact of the printing process on the final values of compressive strength and flexural strength $[17,18,22-26]$. However, several studies implicate that the printed specimens have higher strength than the standard ones $[27,28]$. Besides the mechanical strength, one of the key characteristics in structural design is the modulus of elasticity and the Poisson ratio. A handful of studies have determined the stiffness of the fresh mix, which is directly correlated to buildability, a major property in 3D printing [2,29-37]. Unfortunately, there are not many studies that undertake the topic of modulus of elasticity and Poisson ratio in 3D printed, multilayer hardened structures.

Based on extensive search on Scopus and Web of Science databases (keywords: 3D concrete, 3D mortar, Young's modulus, elastic modulus, and hardened property), the most 
related studies have been selected. A detailed analysis of the results has shown that only several studies have tried to determine the modulus of elasticity of hardened concrete.

Zhang et al. [21] has conducted a study of modulus of elasticity on hardened concrete by cutting out prism specimen $(100 \mathrm{~mm} \times 100 \mathrm{~mm} \times 300 \mathrm{~mm})$ from a multilayer printed structure. Due to low height of the prepared print, the load during the test was applied to specimens in the printing direction. The compressive strength of samples tested in the study was $35.12 \mathrm{MPa}$, the modulus of elasticity $\mathrm{E}=36.6 \mathrm{GPa}$, and the Poisson ratio was 0.28 . The mix prepared for the study had ratio of sand $(<1 \mathrm{~mm})$ to cement of $S / C=1.2$ and $W / C=0.35$. The authors added $2 \%$ of nanoclay and $2 \%$ of silica fume. Unfortunately, the study does not present the results of standard samples; therefore, it is impossible to determine the impact of 3D printing.

Van der Heever et al. [38] has conducted a study of the modulus of elasticity for samples cut out of a printed structure. Cylindrical samples $(\mathrm{d}=28 \mathrm{~mm}, \mathrm{~h}=60 \mathrm{~mm})$ were taken in a perpendicular and longitudinal direction to the layer orientation. The height of the layer in the study was assumed to be $10 \mathrm{~mm}$. The mix had the $w / c=0.46(w / b=0.32)$. Mix was made on CEM II $52.5 \mathrm{~N}$ cement with the maximum size of the aggregate being $4.75 \mathrm{~mm}$, and additional polypropylene fibers $(1=6 \mathrm{~mm})$. Obtained results of the Young's modulus were similar regardless of the specimen orientation (perpendicular $\mathrm{E}_{\mathrm{mod}}=21.6$, $\mathrm{CoV}=6.2 \%$, longitudinal $\mathrm{E}_{\mathrm{mod}}=21.9 \mathrm{GPa}$, and $\mathrm{CoV}=4.8 \%$ ). The article does not present the comparison to standard samples; the authors only refer to the theoretical values of Young's modulus based on the compressive strength of printed specimen. The difference according to authors reached $8 \mathrm{GPa}$ and was seen as a result of differences in porosity $[39,40]$.

$\mathrm{Wu}$ et al. [41] has used a nanoindentation at micro-scale tests and the representative volume element methods (Monte Carlo), as well as results found in the literature, to obtain the results of Young's modulus for a 3D printed structure. The authors have obtained in their theoretical calculations a Young's modulus of 29.17 GPa (Poisson's ration of 0.2), while the initial results taken from literature have shown a $\mathrm{E}_{\mathrm{mod}}=30 \mathrm{GPa}$ with Poisson's ration of 0.22 [42]. It needs to be said that the results were only theoretical and not confirmed experimentally. Individual results of linear elastic constitutive matrix have huge discrepancies, particularly the mean values of the components of effective elasticity matrix. Additionally, the simulation omitted the interlayer transition zone, which can play a major role in the change of mechanical characteristics of 3D printed concrete [43-46].

Zahabizadeh et al. [16] has designed two mixes on a CEM I $42.5(\mathrm{w} / \mathrm{b}=0.31)$, with an aggregate of up to $1 \mathrm{~mm}$ and the addition of fly ash (FA). The mixes had different ratios of cement and FA. Nominal compressive strengths of tested mixes were $58.0 \mathrm{MPa}$ and $75.6 \mathrm{MPa}$. The authors have determined the modulus of elasticity on molded prism samples $(50 \mathrm{~mm} \times 50 \mathrm{~mm} \times 100 \mathrm{~mm}$ ) and samples cut out from printed structure. Both specimen types were cut to the size of $40 \mathrm{~mm} \times 40 \mathrm{~mm} \times 80 \mathrm{~mm}$. The Young's modulus was tested in two directions: perpendicular and longitudinal, to the layer orientation. Obtained results for studied mixes ranged from $27 \mathrm{GPa}$ to $36 \mathrm{GPa}$. The biggest difference in Young's modulus between molded and printed samples was $8 \%$, while for compressive strength the discrepancy increased to $18 \%$. The values of Young's modulus and compressive strength were $8 \%$ and $18 \%$ higher in the longitudinal direction, respectively.

Feng et al. [47] has analyzed the Young's modulus for powder bed fusion prints. In this method, the printed structure has a support that allows for a better compaction between the layers. The determination was performed for a cubic specimen with sides of $70.7 \mathrm{~mm}$ and $50 \mathrm{~mm}$. The height of a single layer was $0.0875 \mathrm{~mm}$. The Young's modulus determined on cubic $70.7 \mathrm{~mm}$ specimen was tested in longitudinal and lateral directions. The results of the determination were $3.6 \mathrm{GPa}$ and $1.9 \mathrm{GPa}$, respectively.

To summarize, only several articles take on the topic of determination of Young's modulus in 3D printed structures. Moreover, none of above-mentioned studies directly refer to the influence of layer number on the results of Young's modulus. Only Van der Heever et al. [38] has performed the tests on the cylindrical samples, where the stress distribution is easy to determine and can be compared to samples made in accordance 
with European standards [48]. This approach allows one to obtain values that can be used in real-life structural design. The authors of that study did not compare the results to standard, molded samples. Other researchers chose prism specimens [16,21,47], which cannot be directly correlated to samples determined by the standards. In some cases, the specimens were not even compared to molded samples [21,47].

The aim of this study is to determine the influence of number of layers and specimen size on the values of Young's modulus in printed structures. The research determines the relation between the specimen size and method of preparation on the values of Youngs modulus. The values are compared to standards samples, which will allow one to implement them for the purpose of structural design.

\section{Materials and Methods}

\subsection{Materials}

The mix used in the study was previously presented in [3,32,49]. The water/binder ratio was 0.3 . Total binder amount is $829 \mathrm{~kg} / \mathrm{m}^{3}$. The binder in mix consists of $70 \%$ of cement (CEM I 52.5R), $20 \%$ of fly ash and $10 \%$ of silica fume. The fly ash used in the study was obtained from a local coal power plant. The aggregate was a fine natural sand of 0-2 $\mathrm{mm}$. A polycarboxylate powder water-reducing admixture was used to adjust the rheological properties of the mix.

The chemical compositions of the materials used are shown in Table 1. Particle size distribution for used materials is presented in Figure 1. The curves for cement, silica fume and fly ash were obtained by laser diffraction method and for fine aggregate by sieve method. Mix composition is given in Table 2.

Table 1. Chemical composition of Portland cement, fly ash and silica fume.

\begin{tabular}{cccc}
\hline Chemical Composition & CEM I 52.5 R [\%] & Fly Ash [\%] & Silica Fume [\%] \\
\hline $\mathrm{SiO}_{2}$ & 19.70 & 54.00 & 94.00 \\
$\mathrm{Al}_{2} \mathrm{O}_{3}$ & 4.93 & 28.40 & - \\
$\mathrm{Fe}_{2} \mathrm{O}_{3}$ & 2.54 & 7.30 & - \\
$\mathrm{CaO}$ & 64.23 & 3.10 & 0.30 \\
$\mathrm{CaCo}_{3}$ & - & - & - \\
$\mathrm{MgO}$ & 1.32 & 2.40 & - \\
$\mathrm{SO}$ & 2.91 & 0.40 & 1.90 \\
$\mathrm{Na}_{2} \mathrm{O}$ & 0.12 & 1.10 & - \\
$\mathrm{K}_{2} \mathrm{O}$ & 0.76 & 2.90 & - \\
$\mathrm{Cl}$ & 0.07 & 0.01 & 0.10 \\
$\mathrm{H}_{2} \mathrm{O}$ & - & - & 0.70 \\
$\mathrm{Na}_{2} \mathrm{Oeq}$ & 0.63 & - & - \\
$\mathrm{LOI}$ & - & - & 3.00 \\
\hline
\end{tabular}

Table 2. Mix composition.

\begin{tabular}{cc}
\hline Material & Amount $\left[\mathbf{k g} / \mathbf{m}^{3}\right]$ \\
\hline Cement CEM I 52.5R & 580 \\
Fly Ash & 166 \\
Silica Fume & 83 \\
Aggregate $0-2$ mm & 1335 \\
Water & 200 \\
Water-reducing admixture & 1.9 \\
\hline
\end{tabular}




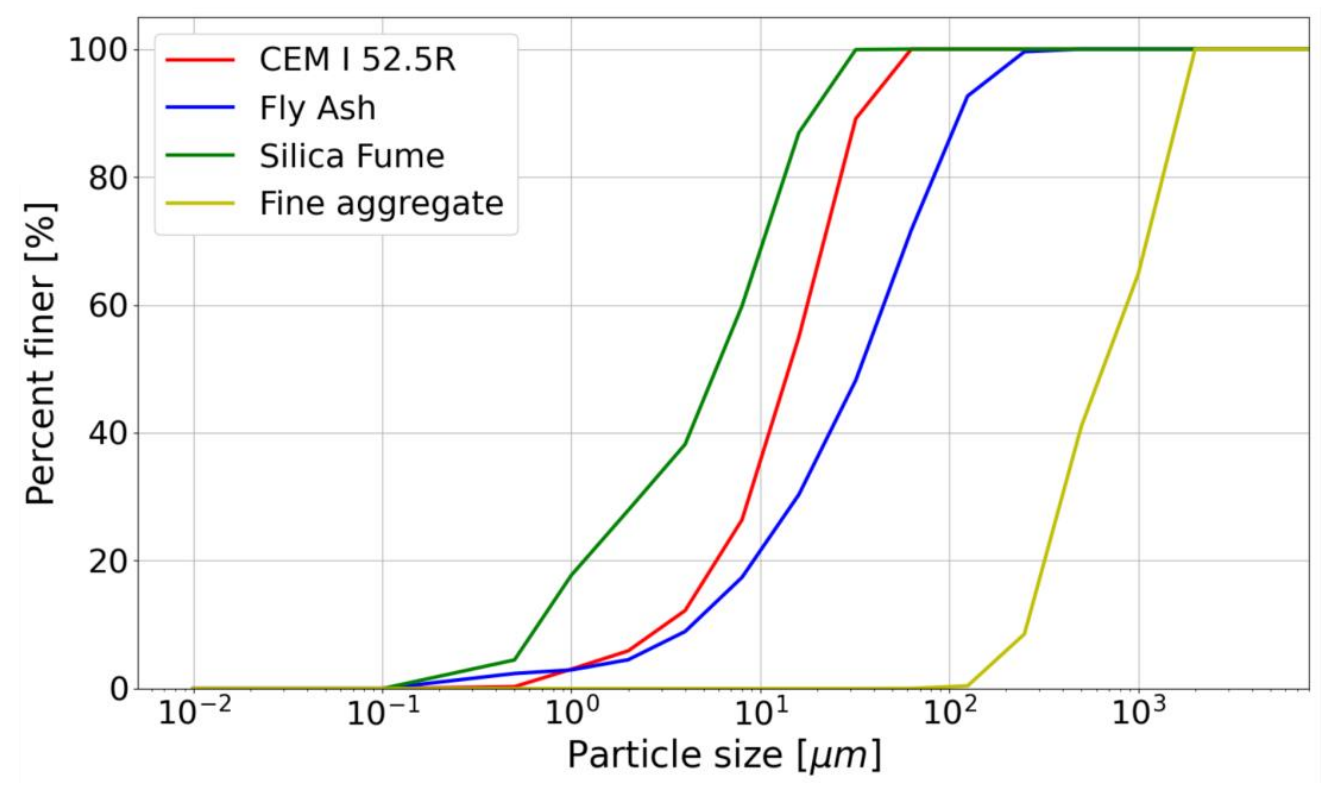

Figure 1. Particle size distribution curve.

\subsection{Experimental Procedure}

The experimental procedure was designed to compare the results of Young's modulus of samples prepared in different way. The study also tries to determine if the size of printed specimen, which results in different number of layers and layer locations, influences this material property. The study determines the correlation of layer number on the mechanical performance of 3D printed elements.

\subsubsection{Mixing Procedure}

A standard $110 \mathrm{~L}$ planetary mixer (Controls, Milan, Italy) was used in this study. All dry materials, including cement, mineral additives, sand and powder water-reducing admixture (PCA) were initially mixed for $5 \mathrm{~min}$. Then, three quarters of the water was added to the mixer. The mix was mixed for $5 \mathrm{~min}$, then the homogeneity of the mix was evaluated. The remaining water was added to improve the workability of the mix.

Mix preparation and printing were made in a laboratory at a temperature of $20{ }^{\circ} \mathrm{C}$ $\left( \pm 2{ }^{\circ} \mathrm{C}\right)$ and relative humidity of $\mathrm{RH}=55 \%( \pm 5 \%)$.

\subsubsection{Fresh Properties}

For the purpose of this study, a constant slump flow of $160 \mathrm{~mm} \pm 10 \mathrm{~mm}$ was assumed. The slump was determined $15 \mathrm{~min}$ after adding the water in accordance with the standard [50]. Similar assumptions for suitability of mixes for 3D printing were proposed in other studies $[3,31,51-54]$. The mix was then pumped to obtain mix for the determination of the buildability.

The buildability was determined in an unconfined uniaxial compression test. A similar test can be found in $[17,30,55,56]$. The test uses cylindrical $\Phi 60 \mathrm{~mm} \times 35 \mathrm{~mm}$ samples. The test allows one to obtain the stress-strain relationship for the examined mix. The test results determine the green strength at failure and Young's Modulus of the mix. This approach allows one to find mix load-bearing and deformation behavior after deposition. Test was performed at a constant displacement rate of $30 \mathrm{~mm} / \mathrm{min}$. The test was performed between 15 and $30 \mathrm{~min}$ after adding water to the dry ingredients. The specimens were formed immediately before testing and compacted manually. The test was performed three times.

The deformation of the specimen during the test was recorded by LVDT (Linear Variable Differential Transformer) displacement transducers (0.01 mm accuracy) (HBM, Darmstadt, Germany) connected to the HBM QuantumX strain gauge bridge (MX840A, HBM, Darmstadt, Germany). The detailed description of the testing bench can be found in [23]. The specimen during the test is presented in Figure 2. 


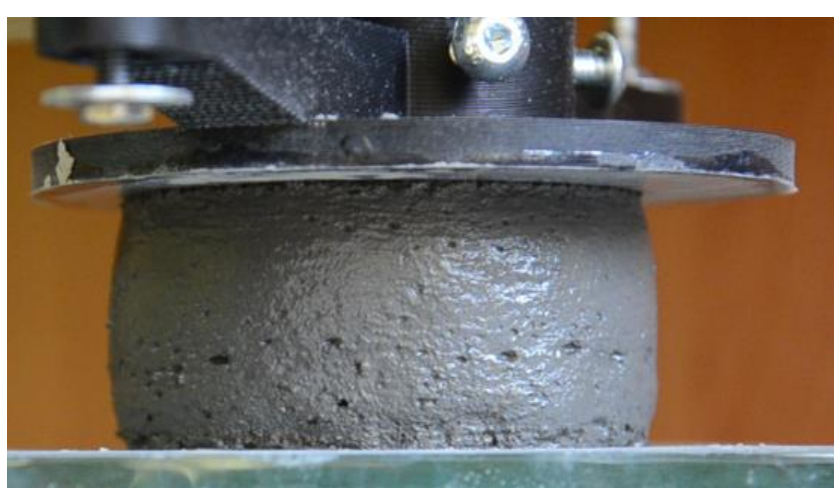

(a)

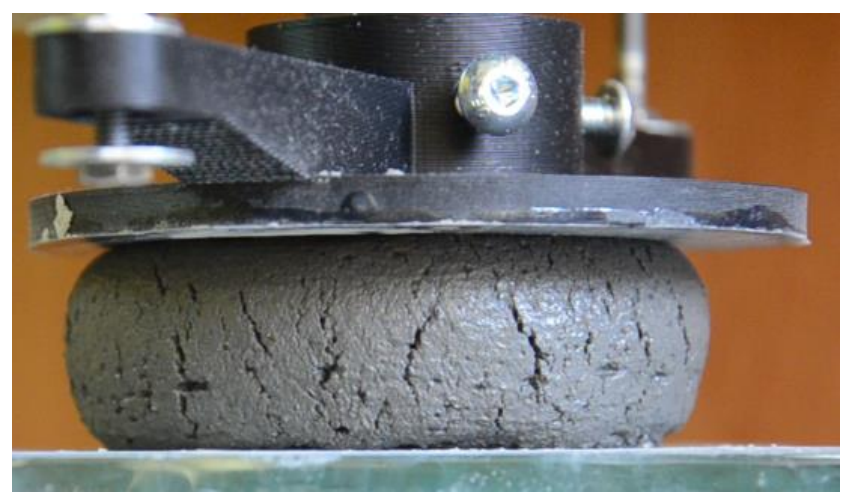

(b)

Figure 2. Specimen during unconfined uniaxial compression test: (a) specimen at the beginning of the test; (b) specimen after the test.

The mix was then initially printed to visually evaluate the path quality. The quality of path was evaluated by following points:

- The sizes of path should be constant;

- The global deformations of path are unacceptable;

- The printed layer must be free of surface defects and cracks (only small minor cracks and defect can be acceptable).

By meeting the mentioned criteria, the mix was accepted for preparation of specimen.

\subsubsection{Specimen Preparation}

Four different methods of preparing samples were considered in this study. Typical cylindrical specimen prepared for ordinary concrete do not reflect the way how the printed concrete works. Therefore, the chosen methods not only address the material properties but also various ways of preparing the samples, which could have a potential application in in-situ testing of printed structure.

The first type was the reference, standard $\Phi 15 \mathrm{~cm} \times 30 \mathrm{~cm}$ cylindrical specimen that was mold-casted. The samples were prepared in a conventional way in accordance with EN 12390-3 [57] and EN 12390-13 [48]. The specimens were left for $24 \mathrm{~h}$ in laboratory before demolding and further curing.

The 3D printed specimens were prepared using the additive manufacturing extrusion method $[6,58]$. For this purpose, a gantry printer $(3 \mathrm{DoF})$ with a concrete rotor-stator pump was used. The system is controlled by a G-Code. For all printed specimen, the constant deposition rate of $0.75 \mathrm{~L} / \mathrm{min}$ was assumed. Depending on the type of specimen described below, the printing speed and pump output was adjusted. The printing setup is presented in Figure 3.

Second type of specimens was prepared by printing within the typical $\Phi 15 \mathrm{~cm} \times 30 \mathrm{~cm}$ mold. The printing path was generated based on a spiral to ensure proper infill of the mold. The pump parameters were set to obtain full cross-section of the specimen. Evaluation of proper pump output and the sample during printing within the mold is presented in Figure 4. The samples were printed directly from a $\Phi 25 \mathrm{~mm}$ hose, rigidly fixed to the printer. Similar to the standard samples, the specimens were left for $24 \mathrm{~h}$ in laboratory before demolding and further curing. 


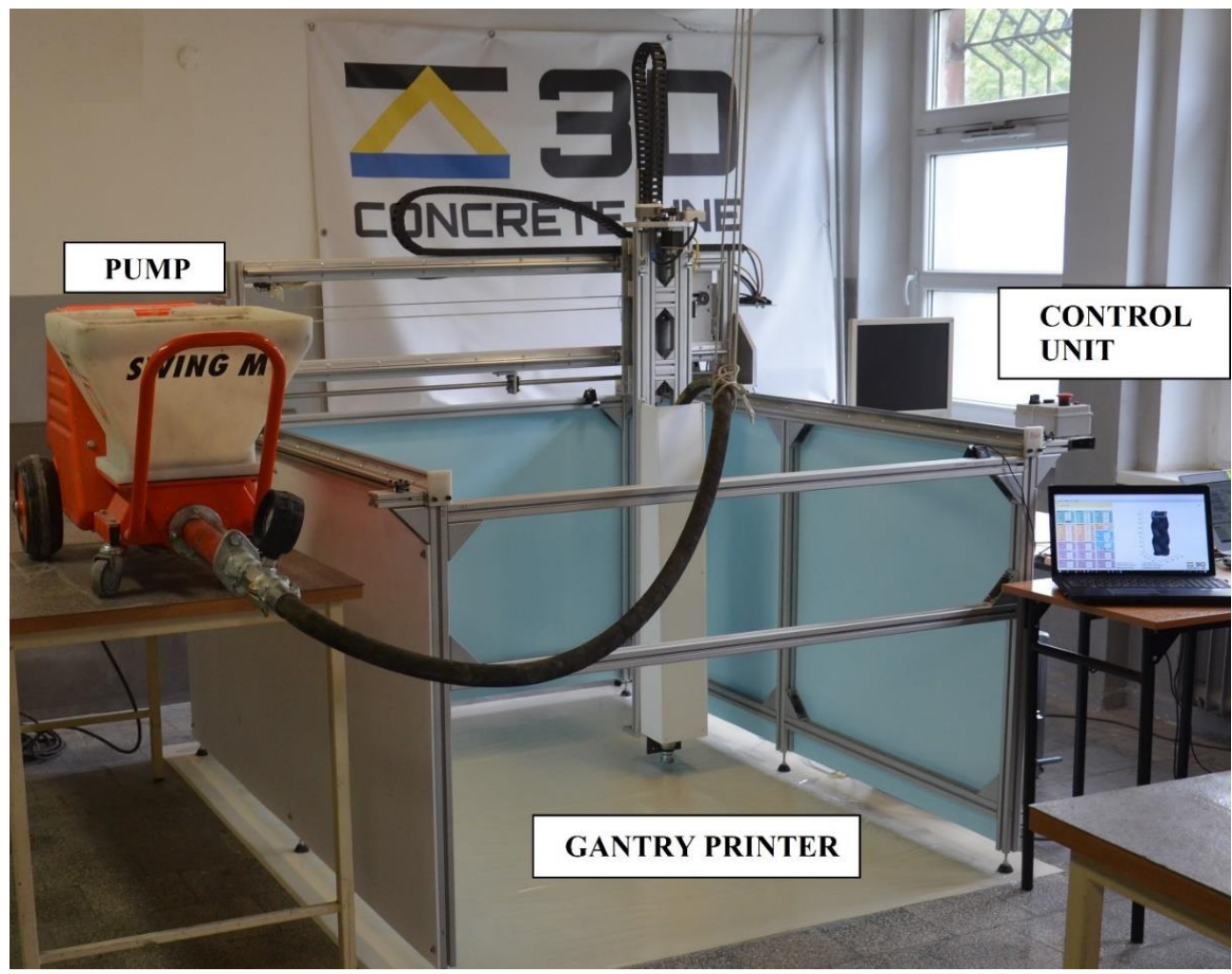

Figure 3. Printing setup used in the study.

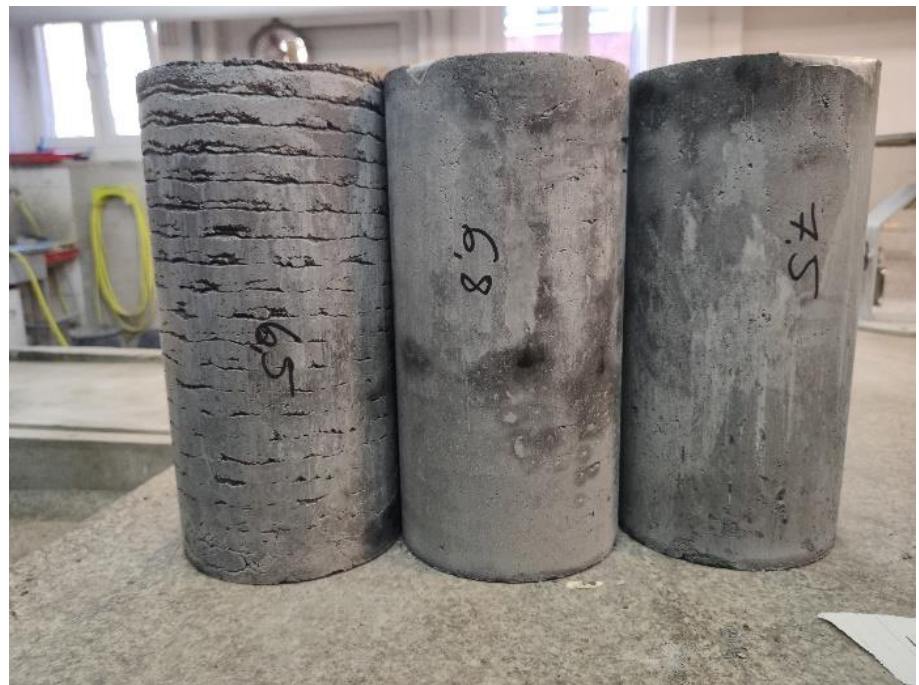

(a)

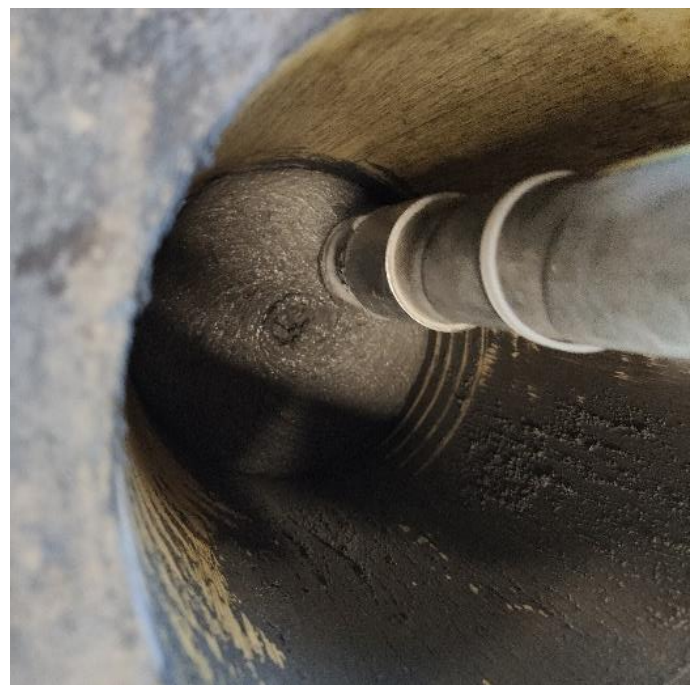

(b)

Figure 4. Samples printed in the mold: (a) evaluation of pump output for samples printed into the mold; (b) view of the printing process.

Third type of specimens was created by printing columns (as presented in Figure 5). The printing was performed using a $\Phi 25 \mathrm{~mm}$ nozzle with a flat end, to provide as even a surface of the layer as possible. The columns had an outer diameter of $150 \pm 5 \mathrm{~mm}$. The outer sides of the specimen were not trowelled. The loose, excessive chunks of the fresh mix were gently removed from the specimen immediately after printing. The samples were then sprayed with a water mist and covered with a PE film for $24 \mathrm{~h}$ before being cured in water for the remaining period. 


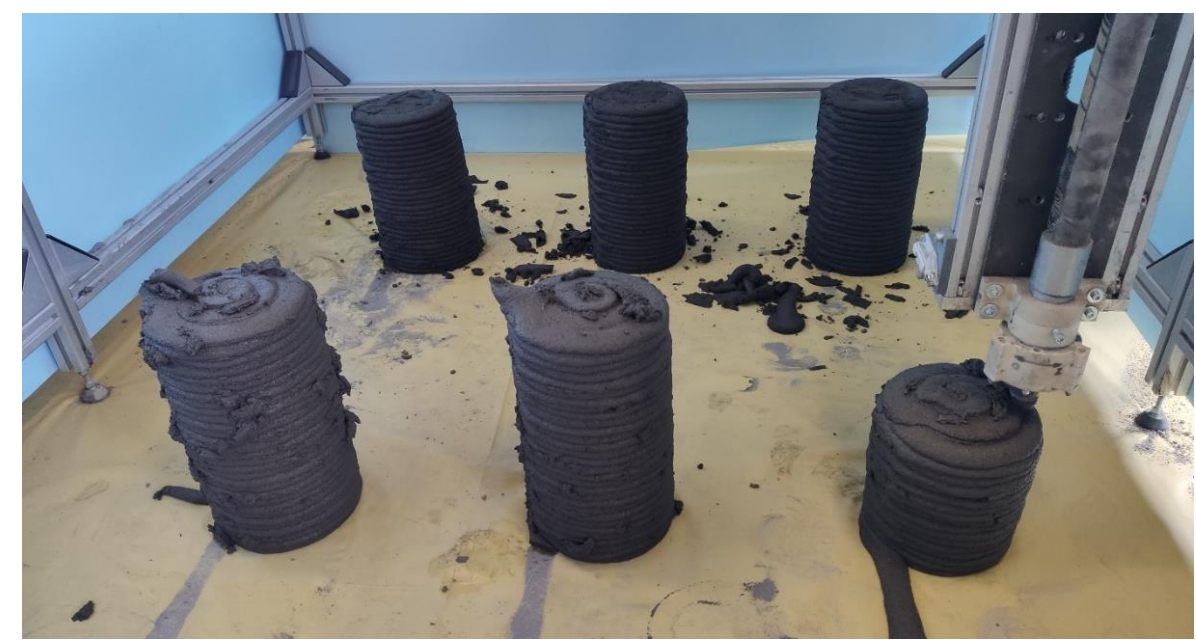

Figure 5. Printing of concrete columns.

The fourth type of specimens was prepared by cutting them from a bigger 3D printed multi-layer block. The initial block was printed using a $\Phi 25 \mathrm{~mm}$ nozzle with parallel layers. The printing speed was adjusted to obtain good visual vertical adhesion of the layers. The specimen were cut in four different sizes to determine the influence of the number of layers on the mechanical characteristics. The diameter of cut out samples chosen for the study was $44 \mathrm{~mm}, 74 \mathrm{~mm}, 99 \mathrm{~mm}$ and $144 \mathrm{~mm}$. The cutting was made using typical diamond saw for concrete and stone. The sizes were chosen based on available core drill sizes. The cut-out samples were then cut to reach the ratio of length to diameter of $1 / d=2 \pm 0.1$. The schematics of drilled samples are presented in Figure 6.

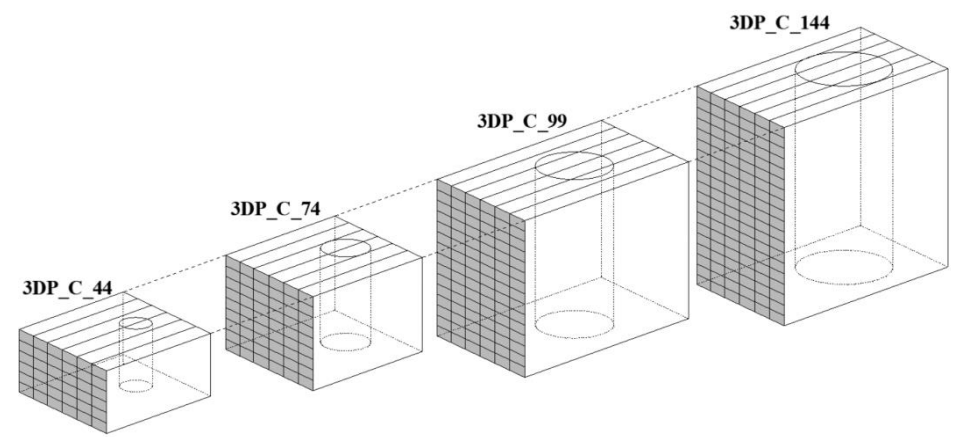

(a)

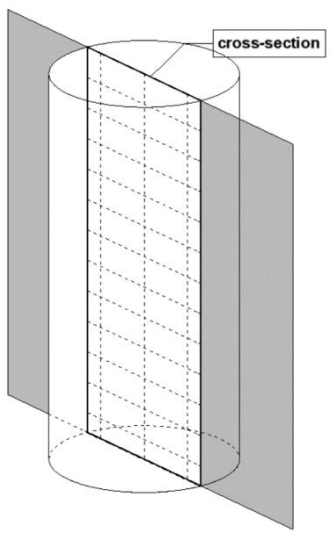

(b)

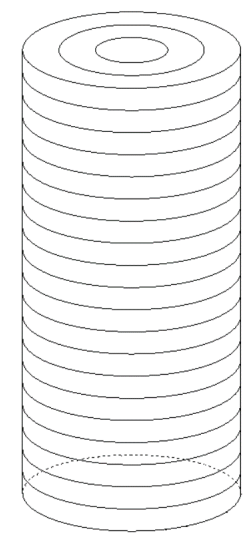

(c)

Figure 6. Schematics of samples: (a) core drilled from printed structure-plan with layers orientation; (b) core drilled from printed structure-example of cross-section; and (c) freely $3 \mathrm{~d}$ printed columns and specimens printed into mold. 
The notation of all samples prepared in the study is as follows:

- $\quad$ STDR—standard mold-casted specimens $\Phi 15 \mathrm{~cm} \times 30 \mathrm{~cm}$;

- 3DP_M-specimens 3D printed into a $\Phi 15 \mathrm{~cm} \times 30 \mathrm{~cm}$ mold;

- 3DP_F-freely 3D printed columns approx. $\Phi 15 \mathrm{~cm} \times 30 \mathrm{~cm}$;

- $3 D P \_C \_X-3 D$ printed specimens cut from a block. The $X$ stands for a diameter of the sample in $\mathrm{mm}$.

All specimens after initial $24 \mathrm{~h}$ curing time were cured in water at $20 \pm 2{ }^{\circ} \mathrm{C}$ for additional 26 days before the tests. The samples were then taken out and surface-dried to prepare them for attaching the strain gauges (Techno-Mechanik, Gdańsk, Poland). The specimen was stored for the last $24 \mathrm{~h}$ in laboratory conditions. The total curing took 28 days. Notations and sample characteristics were shown in Table 3.

Table 3. Notations and sample characteristics.

\begin{tabular}{ccccc}
\hline Group & Type & Diameter [mm] & Height [mm] & Number of Layers \\
\hline \multirow{4}{*}{ I } & STDR & 150 & 300 & - \\
& 3DP_M & 150 & $300 \pm 10$ & $20 \pm 1$ \\
& 3DP_F & $150 \pm 10$ & $300 \pm 10$ & $20 \pm 1$ \\
\hline \multirow{4}{*}{ II } & 3DP_C_44 & 44 & $90 \pm 10$ & $6 \pm 1$ \\
& 3DP_C_74 & 74 & $160 \pm 10$ & $11 \pm 1$ \\
& 3DP_C_99 & 99 & $200 \pm 10$ & $13 \pm 1$ \\
& 3DP_C_144 & 144 & $300 \pm 10$ & $20 \pm 1$ \\
\hline
\end{tabular}

\subsubsection{Young's Modulus and Compressive Strength}

For the purpose of compressive strength and Young's modulus determination, six samples were prepared for each specimen type. The samples were prepared and tested in accordance with [48]. The upper and bottom parts of the specimen were either cut off to obtain even and parallel surfaces or if possible, capped with high-strength fast setting mix.

The Young's modulus test was performed in accordance with [48]. Each specimen $\Phi 15 \mathrm{~cm} \times 30 \mathrm{~cm}$ was prepared by symmetrically attaching three vertical and two horizontal strain gauges with a base of $75 \mathrm{~mm}$ and k-Gauge factor of 2.15. For core drilled specimen smaller strain gauges, with bases of $20 \mathrm{~mm}$, were installed. Examples of samples with strain gauges installed are presented in Figure 7. The strain gauges were connected in a half-bridge. The measurements were recorded by the HBM UPM 60 device (HBM, Darmstadt, Germany).

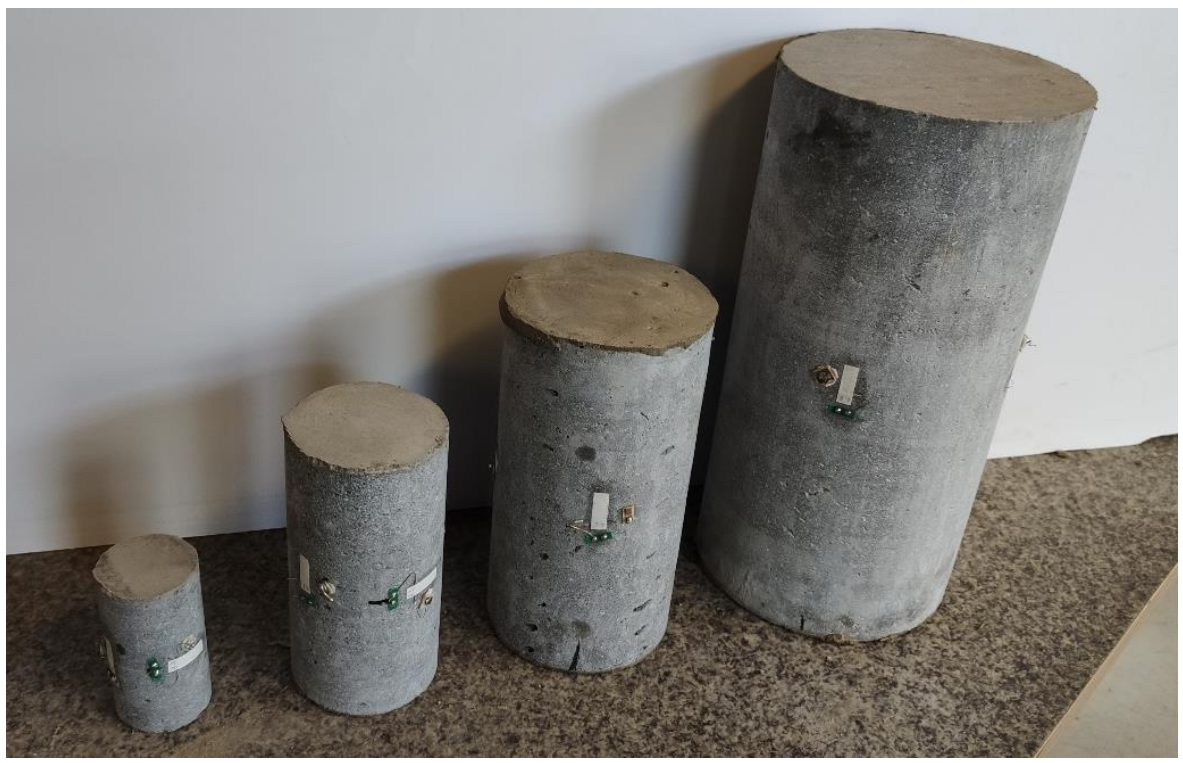

Figure 7. Core drilled specimens with strain gauges installed on them. 


\section{Results}

\subsection{Unconfined Uniaxial Compression Test}

The unconfined uniaxial compression test was used to determine the buildability of the mix. The mixes were tested between 15 and $30 \mathrm{~min}$ after adding water to the mix, which corresponds to time of printing. Figure 8 presents the stress-strain relation $\sigma(\epsilon)$. The dots represent each individual measurement, while line corresponds to the mean values between two adjacent results.

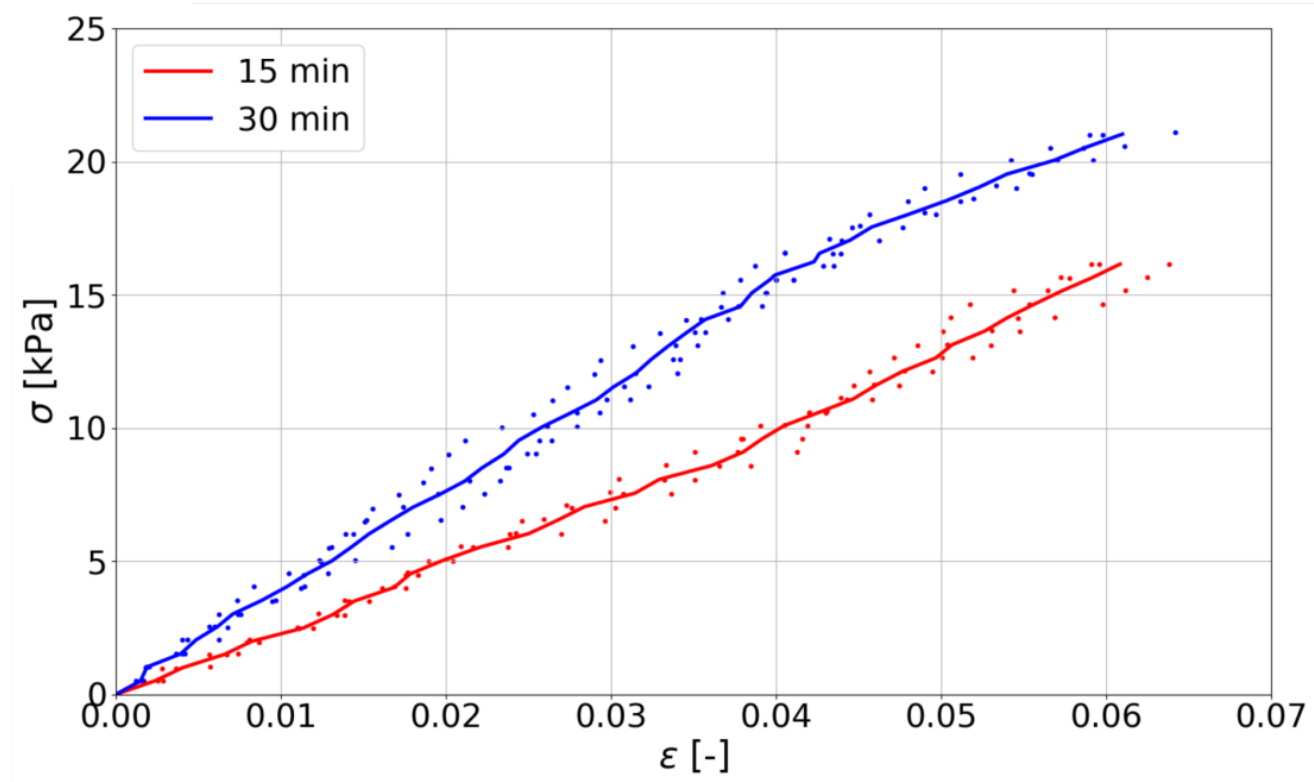

Figure 8. The stress-strain curve for mixes.

Table 4 presents the mean values obtained in the study. The green strength and Young's modulus value, calculated as a slope of $\sigma(\epsilon)$ (see [59]), has been presented.

Table 4. Mechanical properties of 3D printed mix.

\begin{tabular}{ccccc}
\hline \multirow{2}{*}{ Time } & \multicolumn{2}{c}{ Green Strength [kPa] } & \multicolumn{2}{c}{ Young's Modulus [kPa] } \\
& Mean [kPa] & CoV [\%] & Mean [kPa] & CoV [\%] \\
\hline $15 \mathrm{~min}$ & 16.15 & 4.30 & 263.00 & 3.88 \\
$30 \mathrm{~min}$ & 21.03 & 3.20 & 359.32 & 3.52 \\
\hline
\end{tabular}

The mixture during printing can transfer loads between $16.15 \mathrm{kPa}$ and $21.03 \mathrm{kPa}$. In addition, its stiffness ranges between $263 \mathrm{kPa}$ and $359.32 \mathrm{kPa}$. Similar results were obtained by Esposito et al. [52], where the compressive strength (green strength) at 15 to $30 \mathrm{~min}$ was in the range of $11.64 \mathrm{kPa}$ to $26.04 \mathrm{kPa}$ depending on the type of mixture and test method. The Young's modulus in their study was between $252 \mathrm{kPa}$ and $488 \mathrm{kPa}$. Wolfs et al. [60] have obtained strength in the range of $6.99 \mathrm{kPa}$ to $10.87 \mathrm{kPa}$ and Young's modulus in the range of $54.42 \mathrm{kPa}$ to $98.52 \mathrm{kPa}$. Ding et al. [34] obtained compressive strength in the range of 9.51 to $45 \mathrm{kPa}$ and Young's modulus between $29 \mathrm{kPa}$ and $280 \mathrm{kPa}$. In summary, the values obtained in this study can be considered as correct and meeting the requirements for 3D printed mixes. Results are corroborated by other studies $[3,23,29,34,52,59,60]$.

\subsection{Young's Modulus and Compressive Strength}

Determination of the mechanical parameters of studied samples is presented in Table 5 . Mean values of compressive strength $f_{c m}$, Young's modulus $E_{c m}$ and Poisson's ratio $\vartheta_{c m}$ 
with coefficient of variations $\mathrm{CoV}$ are given. Additionally, a percentage strength relation to standard specimens STDR is given calculated based on (1):

$$
X_{\text {change }}=\frac{X_{c m}-X_{s t}}{X_{s t}} \cdot 100 \%
$$

where:

- $\quad X_{\text {change }}$-percentage change $\left(E_{\text {change }}-\right.$ for Young's modulus, $f_{\text {change }}$-for compressive strength, $\vartheta_{\text {change }}-$ for Poisson's ratio);

- $X_{s t}$-mean value obtained for standard specimens;

- $X_{c m}$-mean value obtained on a specific specimens type.

Table 5. Results of compressive strength, Young's modulus and Poisson's ratio determination.

\begin{tabular}{|c|c|c|c|c|c|c|c|c|c|}
\hline Specimen & $\begin{array}{c}f_{c m} \\
{[\mathrm{MPa}]}\end{array}$ & $\begin{array}{l}\mathrm{CoV} \\
{[\%]}\end{array}$ & $\begin{array}{c}f_{\text {change }} \\
\text { (1) }\end{array}$ & $\begin{array}{c}E_{c m} \\
{[\mathrm{GPa}]}\end{array}$ & $\begin{array}{l}\mathrm{CoV} \\
{[\%]}\end{array}$ & $\begin{array}{c}E_{\text {change }} \\
\text { (1) }\end{array}$ & $\begin{array}{l}\vartheta_{c m} \\
{[-]}\end{array}$ & $\begin{array}{l}\mathrm{CoV} \\
{[\%]}\end{array}$ & $\begin{array}{c}\vartheta_{\text {change }} \\
\text { (1) }\end{array}$ \\
\hline STDR & 85.72 & $5.5 \%$ & - & 39.93 & $1.7 \%$ & - & 0.19 & $3.5 \%$ & - \\
\hline 3DP_M & 65.03 & $6.5 \%$ & $-24.1 \%$ & 38.25 & $2.4 \%$ & $-4.2 \%$ & 0.19 & $9.2 \%$ & $4.7 \%$ \\
\hline 3DP_F & 48.77 & $7.2 \%$ & $-43.1 \%$ & 32.01 & $6.8 \%$ & $-19.8 \%$ & 0.21 & $7.4 \%$ & $13.3 \%$ \\
\hline 3DP_C_44 (C_44) & 75.42 & $9.8 \%$ & $-12.0 \%$ & 36.15 & $7.5 \%$ & $-9.5 \%$ & 0.18 & $6.5 \%$ & $-2.8 \%$ \\
\hline 3DP_C_74 (C_74) & 68.17 & $6.6 \%$ & $-20.5 \%$ & 35.71 & $5.0 \%$ & $-10.6 \%$ & 0.18 & $8.5 \%$ & $-3.0 \%$ \\
\hline 3DP_C_99 (C_99) & 63.01 & $7.5 \%$ & $-26.5 \%$ & 33.70 & $5.9 \%$ & $-15.6 \%$ & 0.17 & $9.5 \%$ & $-7.5 \%$ \\
\hline 3DP_C_144 (C_144) & 60.18 & $5.5 \%$ & $-29.8 \%$ & 32.44 & $1.7 \%$ & $-18.8 \%$ & 0.20 & $7.5 \%$ & $6.7 \%$ \\
\hline
\end{tabular}

The failure mechanism of studied samples is presented in Figure 9. Comparison of results is presented in Figures 10-12.

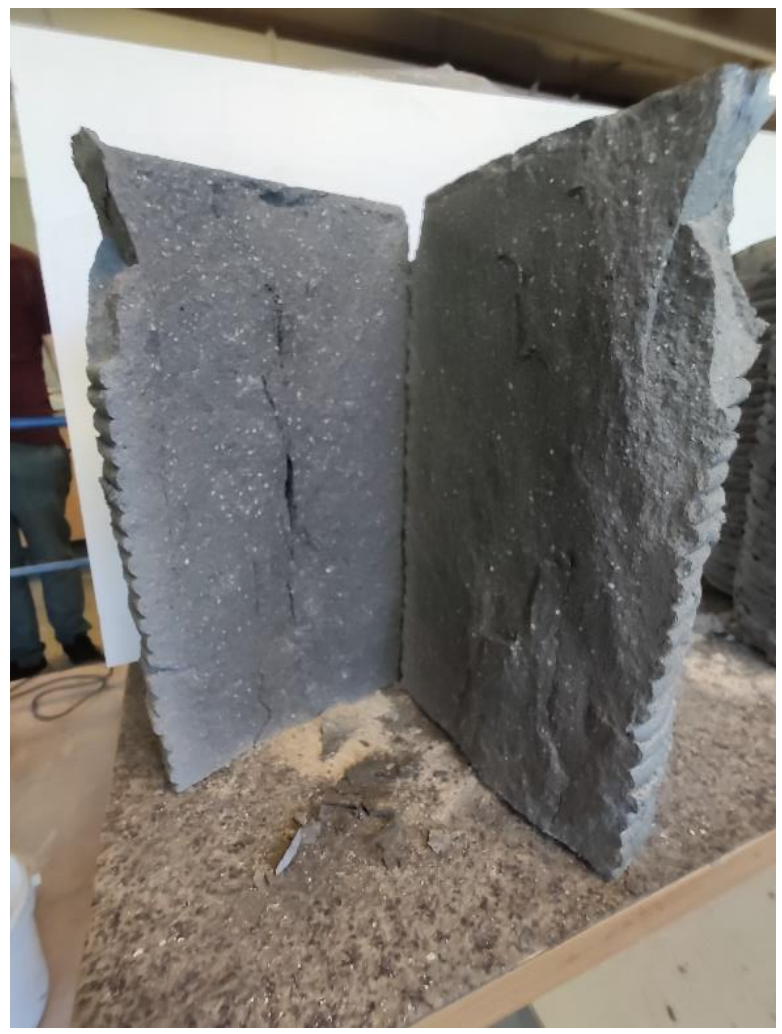

(a)

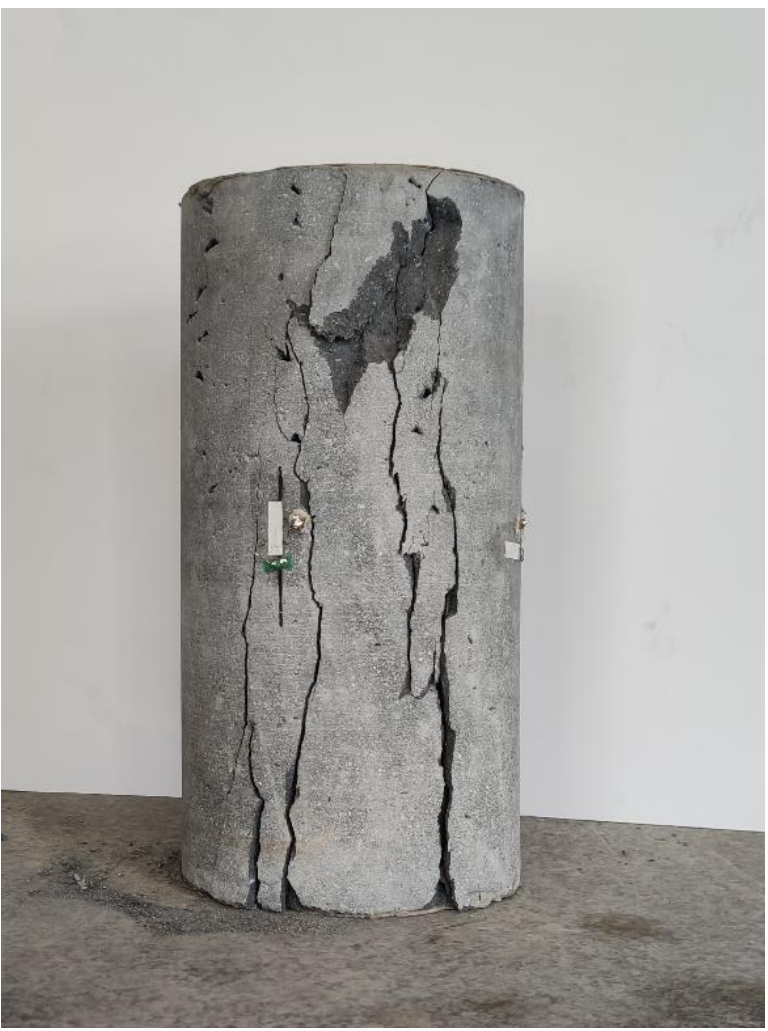

(b)

Figure 9. Failure mechanism of specimen: (a) freely printed column 3DP_F; (b) specimen cut out 3DP_C_144. 


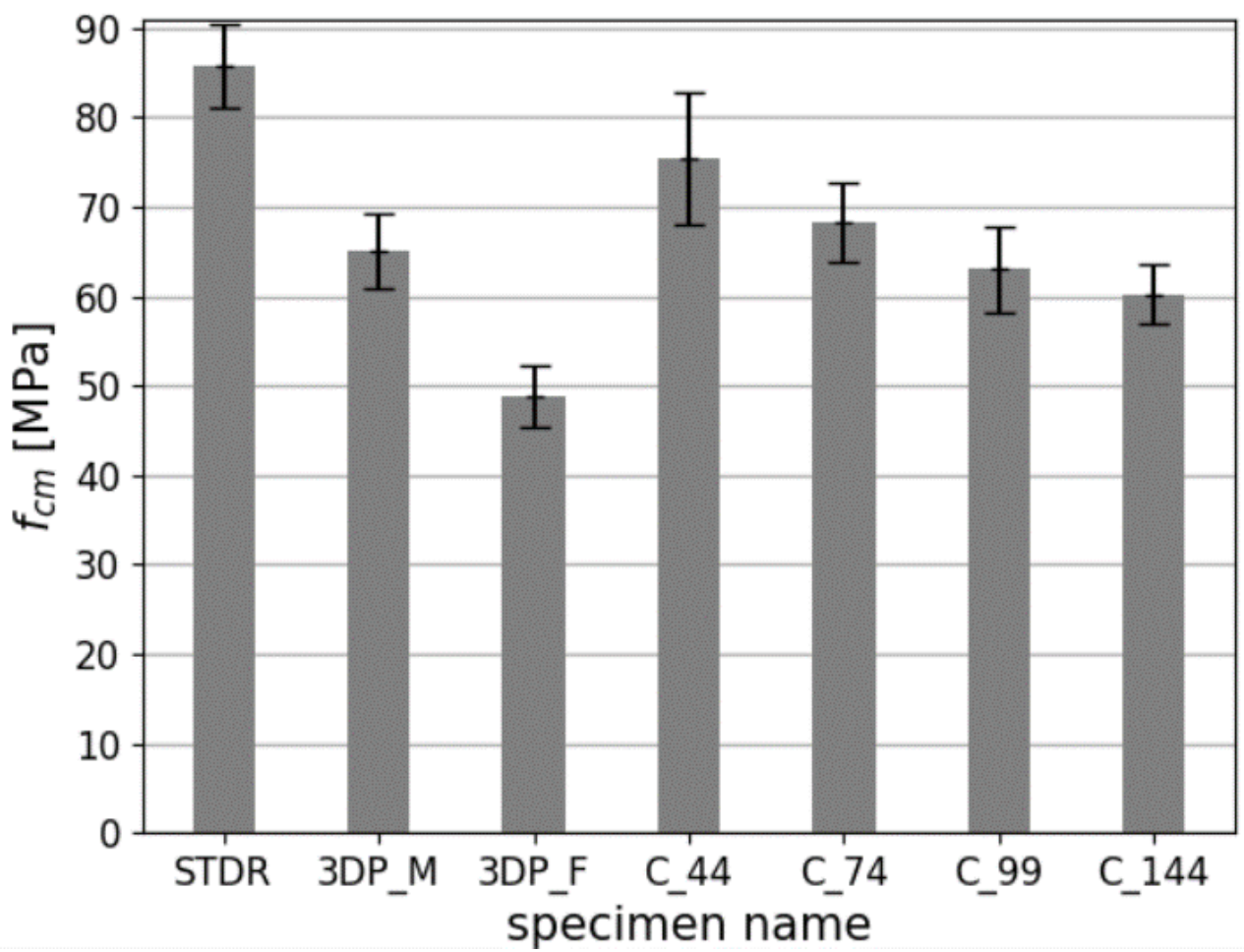

Figure 10. Comparison of the compressive strengths of studied specimens.

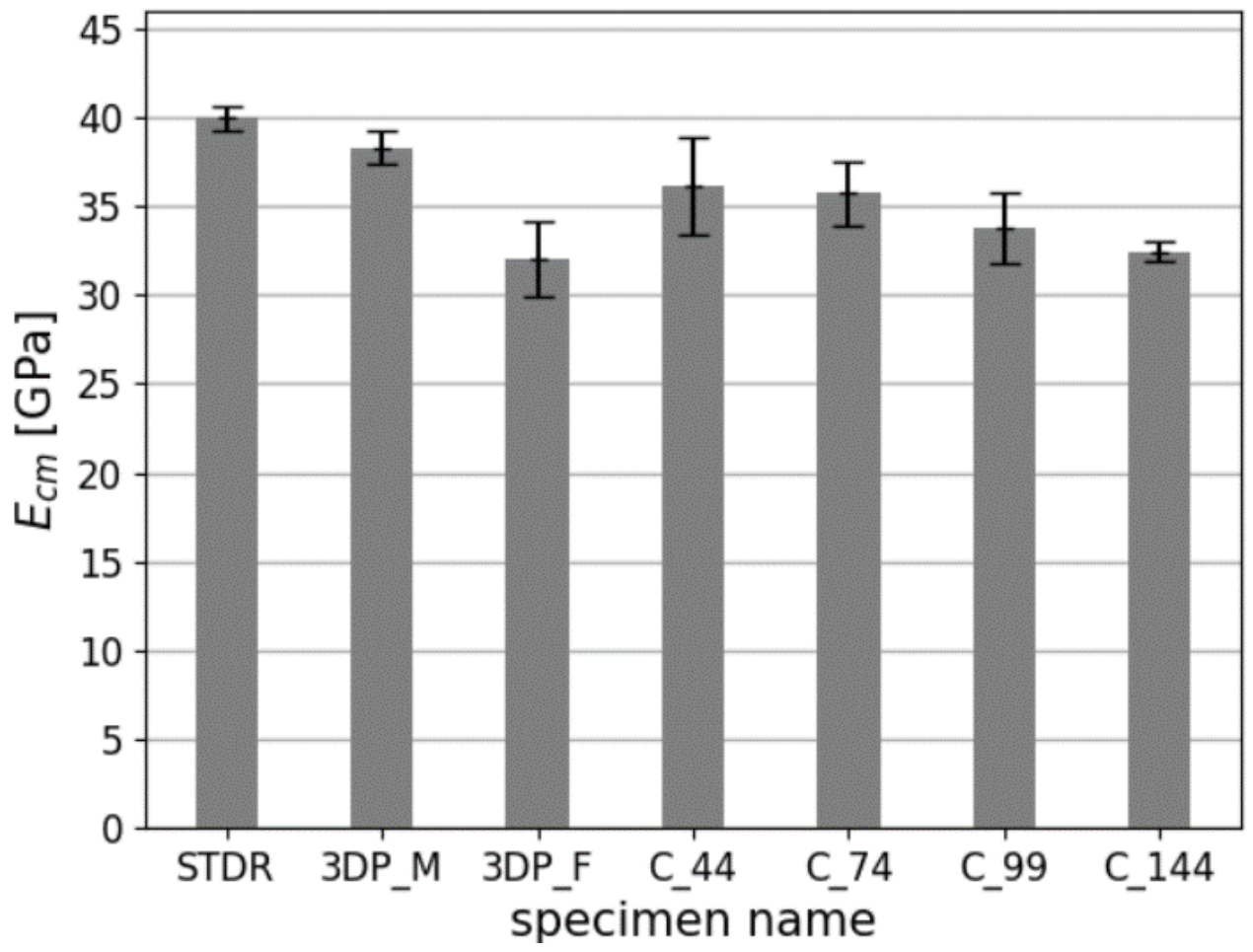

Figure 11. Comparison of the Young's modulus of studied specimens. 


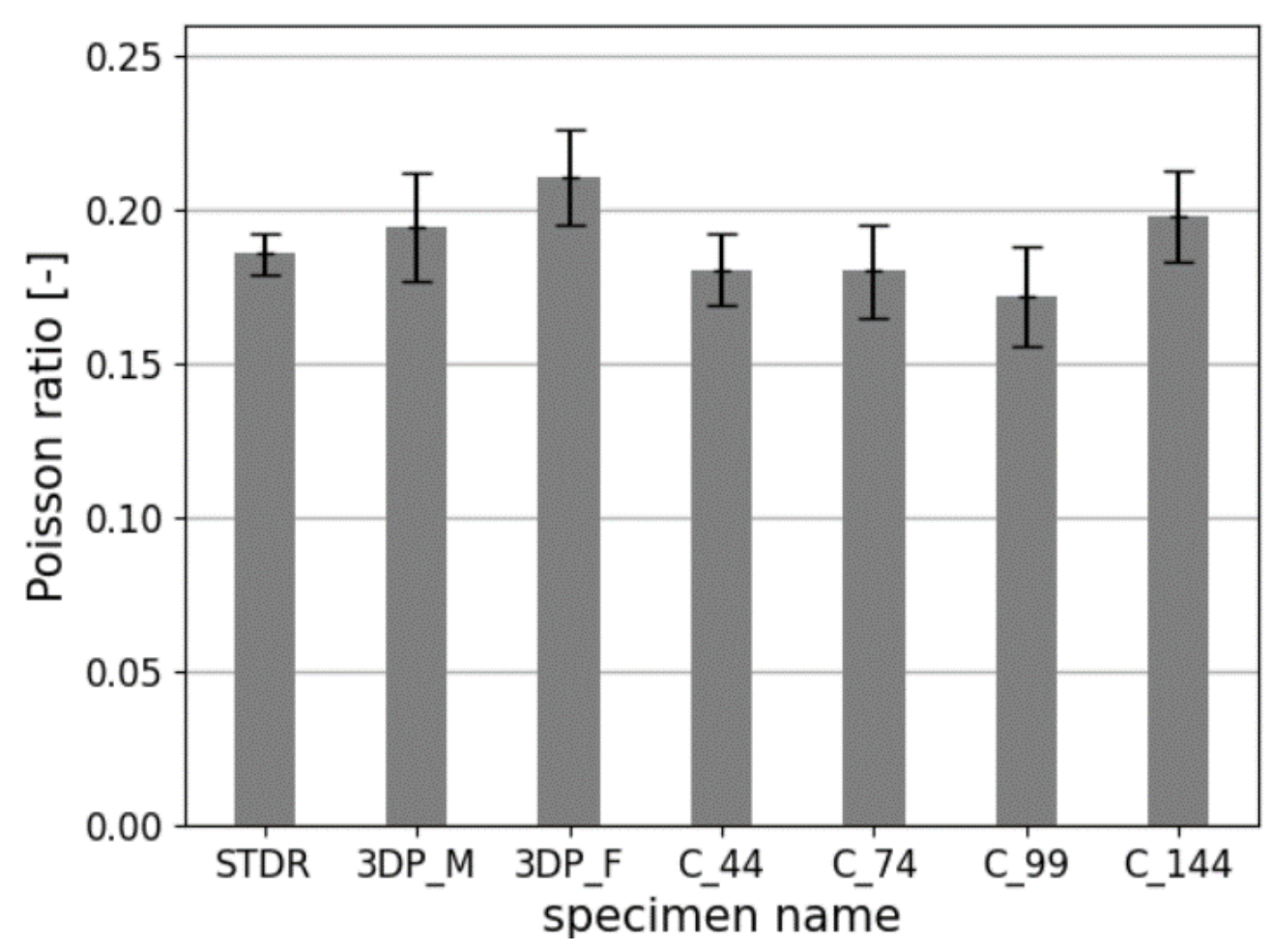

Figure 12. Comparison of the Poisson's ratios of studied specimens.

In case of the compressive strength, the highest was achieved by the standard samples (STDR), which seems to be a proper result considering other publications on 3D printing where standard and printed samples where compared [18,22,24,25,61]. The reduction in strength for printed samples ranged from $12 \%$ to $43.1 \%$. The lowest compressive strength value was achieved by the 3DP_F specimen (printed cylindrical specimen without any lateral support). For this specimen, the reduction in strength relative to the standard specimen was the greatest, as much as $43.1 \%$. This can also be considered correct because this sample was printed without any side support, resulting in worse compaction at the interlayer zone $[19,39,40]$. Other samples had either lateral support in the form of a mold (3DP_M samples) or in the form of surrounding layers of printed material-lateral elastic support (samples 3DP_C_44 to C_144). The strength reduction for samples other than the 3DP_F is between $12 \%$ and $29.8 \%$.

For Young's modulus, the difference between the results is less visible. The difference between freely printed samples (3DP_F) and STDR samples reached 19.8\%. The highest results of the Young's modulus were observed for the STDR samples ( $\mathrm{E}=39,93 \mathrm{GPa})$.

No clear correlation between the method of preparing the samples and Poisson's ratio was observed. The values for all samples were between 0.17 and 0.21 , corresponding to $\mathrm{a}-13.3 \%$ to $+7.5 \%$ change compared to STDR samples. As the CoV for all specimens is rather low, the values obtained in this study concur with the EN 1992-1-1 [62] standard, which assumes the Poisson's ratio of $\vartheta_{c m}=0.2$.

Figure 13 presents the statistical correlation between the number of layers, and the compressive strength and Young's modulus of specimen. The analysis was performed for the samples cut from a bigger block (3DP_C_X) and a freely printed column (3DP_F), to exclude the possible compaction of layers that could occur in samples printed in the mold. 


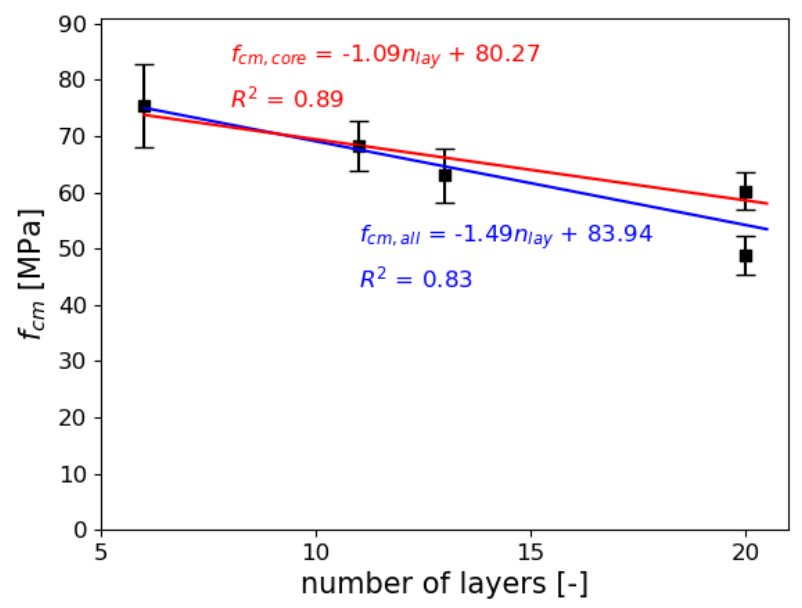

(a)

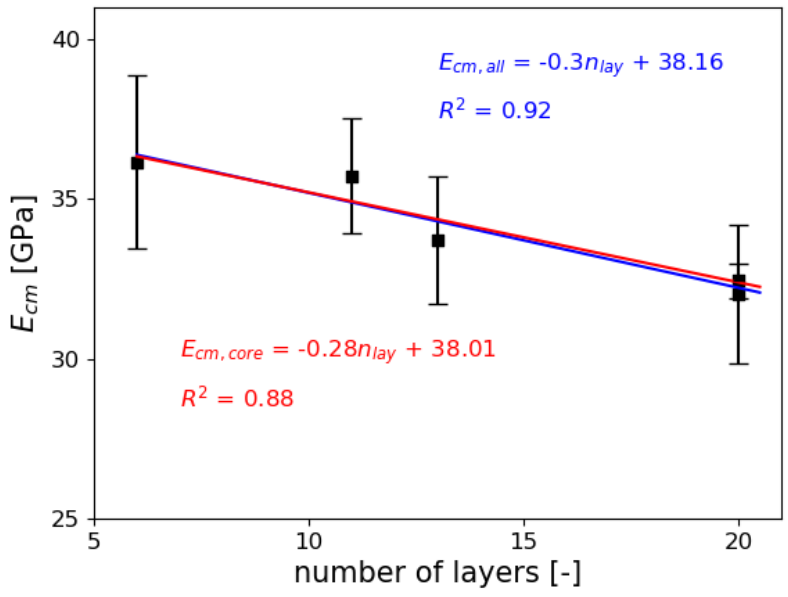

(b)

Figure 13. The correlation between the number of layers and (a) compressive strength, (b) Young's modulus.

A linear regression was applied to analyze the results of this study. Analysis was performed for the compressive strength and Young's modulus. The linear regression was calculated for two groups of samples:

- $\quad f_{c m, a l l}$ and $E_{c m, \text { all }}$-all cut out samples 3DP_C_X and 3DP_F

- $\quad f_{c m, \text { core }}$ and $E_{c m, \text { core }}$-only cut out samples, excluding 3DP_F

Those two groups were chosen to determine if the sample preparation method (freely printed column or core drilled samples) for 3D printed concrete influences the mechanical properties. Figure 13 presents also the value of the $R^{2}$ (coefficient of determination) as well as standard deviation of the results.

Figure 13a presents the analysis of the results for the compressive strength obtained in the study. The compressive strength of samples decreases with the increase of the number of layers. As seen in the linear regression for all samples $\left(f_{c m, a l l}\right)$, the coefficient of determination $\mathrm{R}^{2}=0.83$. This means that the correlation of the results is not satisfactory. The main reason behind it is the difference between the results of the biggest core drilled samples (3DP_C_144) and the freely printed samples (3DP_F). The latter has a significantly lower mean compressive strength, which results in the decrement of the $\mathrm{R}^{2}$ value. Freely printed samples do not have any lateral support, whereas the core drilled samples were initially restricted by surrounding layers. In case of the second group of samples, where the 3DP_F was excluded, the value of $R^{2}$ was 0.89 , which is much closer to the value considered as strong correlation of the results.

Figure $13 \mathrm{~b}$ presents the results of the analysis of Young's modulus. As in the analysis of the compressive strength, the Young's modulus decreases with the increase of the number of layers. This confirms the assumption that mechanical material properties will similarly change with the change of layer number. Looking at the results for the biggest printed samples (3DP_F and 3DP_C_144), the differences in the values of Young's modulus were insignificant and are within the values of $\mathrm{CoV}$. The value of the coefficient of determination for all printed samples $\left(E_{c m, a l l}\right)$ was $\mathrm{R}^{2}=0.92$, while only for core printed samples $\left(E_{c m, c o r e}\right)$ was $R^{2}=0.88$. Both values prove the good correlation of the results. It is worth noticing that the percentage differences in the Young's modulus is close to the values of $\mathrm{CoV}$, which proves that the differences are insignificant.

\section{Conclusions}

The paper presents the influence of number of layers and preparation method on the values of Young's modulus of 3D printed concrete. Obtained results for 3D printed samples were compared to standard cylindrical samples. The study extends the knowledge on the 
determination of Young's modulus for 3D printed structures. Following conclusions have been drawn:

- The bigger the specimen, the lower the mechanical performance of cut-out samples.

- The higher the number of layers, the lower the value of compressive strength of printed samples. The strength reduction compared to standard cylindrical sample was the highest for freely printed columns (approximately 43\%). The strength reduction was lower for samples printed into a mold or cut out from a bigger printed block.

- The higher the number of layers, the lower the value of Young's modulus of printed samples. The difference between the biggest printed sample and the standard sample reached $20 \%$.

- Samples printed into a mold or cut out from a bigger printed block had better mechanical performance than freely printed columns. This is caused by lateral restriction of concrete due to either mold itself or surrounding layers.

- The value of Poisson's ratio for printed samples in this study differed by $\pm 13 \%$ from the standard samples.

The article presents different ways of preparing the specimen and compares them. None of the printed specimen came close to the values obtained for a standard specimen. This means that the approach to preparing samples for evaluation of 3D printed elements should be reconsidered. The community needs to determine a single, standards methods for determining material parameters of 3D printed concrete for real-life structural applications. Each of the studied methods of preparing the samples has its disadvantages. Samples printed within a formwork require hose extension and can be bothersome. The samples freely printed as columns have variations of dimensions and do not exactly reflect the deformation that would occur when printing higher structures. The samples cut from a bigger printed block can have changed properties due to the cutting itself.

The results of this study has shown a significant reduction in compressive strength and Young's modulus of 3D printed structures in regard to standard samples. This shows the importance of including the reduction factors in designing protocols of $3 \mathrm{D}$ printed structural elements. It is necessary not only to include the reduction in compressive or flexural strengths that can be found in other studies $[18,22,61]$ but also the reduced values of the Young's modulus.

Author Contributions: Conceptualization, S.S., M.T. and K.F.; methodology S.S., M.T. and K.F.; formal analysis, S.S.; investigation, M.T., K.F., M.H., N.O. and S.S.; data curation, S.S.; writingoriginal draft preparation, S.S., M.T. and K.F., writing-review and editing, M.T., K.F., M.H. and N.O.; supervision, S.S., M.T. All authors have read and agreed to the published version of the manuscript.

Funding: This research received no external funding.

Institutional Review Board Statement: Not applicable.

Informed Consent Statement: Not applicable.

Data Availability Statement: The data presented in this study are available upon reasonable request from the corresponding author.

Conflicts of Interest: The authors declare no conflict of interest.

\section{References}

1. Kazemian, A.; Yuan, X.; Cochran, E.; Khoshnevis, B. Cementitious materials for construction-scale 3D printing: Laboratory testing of fresh printing mixture. Constr. Build. Mater. 2017, 145, 639-647. [CrossRef]

2. Le, T.T.; Austin, S.A.; Lim, S.; Buswell, R.A.; Gibb, A.G.F.; Thorpe, T. Mix design and fresh properties for high-performance. Mater. Struct. 2012, 45, 1221-1232. [CrossRef]

3. Skibicki, S.; Kaszyńska, M.; Wahib, N.; Techman, M.; Federowicz, K.; Zieliński, A.; Wróblewski, T.; Olczyk, N.; Hoffmann, M. Properties of Composite Modified with Limestone Powder for 3D Concrete Printing. In Proceedings of the Second RILEM International Conference on Concrete and Digital Fabrication; Bos, F.P., Lucas, S.S., Wolfs, R.J.M., Salet, T.A.M., Eds.; Springer International Publishing: Cham, Switzerland, 2020; pp. 125-134, ISBN 978-3-030-49916-7. 
4. Cuevas, K.; Chougan, M.; Martin, F.; Ghaffar, S.H.; Stephan, D.; Sikora, P. 3D printable lightweight cementitious composites with incorporated waste glass aggregates and expanded microspheres-Rheological, thermal and mechanical properties. J. Build. Eng. 2021, 44, 102718. [CrossRef]

5. Wangler, T.; Roussel, N.; Bos, F.P.; Salet, T.A.M.; Flatt, R.J. Digital Concrete: A Review. Cem. Concr. Res. 2019, 123, 105780. [CrossRef]

6. Buswell, R.A.; Leal de Silva, W.R.; Jones, S.Z.; Dirrenberger, J. 3D printing using concrete extrusion: A roadmap for research. Cem. Concr. Res. 2018, 112, 37-49. [CrossRef]

7. Skibicki, S.; Kaszyńska, M.; Techman, M. Maturity testing of 3D printing concrete with inert microfiller. MATEC Web Conf. 2018, 219, 3008. [CrossRef]

8. Federowicz, K.; Kaszyńska, M.; Zieliński, A.; Hoffmann, M. Effect of Curing Methods on Shrinkage Development in 3D-Printed Concrete. Materials 2020, 13, 2590. [CrossRef]

9. Sikora, P.; Chougan, M.; Cuevas, K.; Liebscher, M.; Mechtcherine, V.; Ghaffar, S.H.; Liard, M.; Lootens, D.; Krivenko, P.; Sanytsky, M.; et al. The effects of nano- and micro-sized additives on 3D printable cementitious and alkali-activated composites: A review. Appl. Nanosci. 2021, 6, 100135. [CrossRef]

10. Abdullah, A.; Taha, M.; Rashwan, M.; Fahmy, M. Efficient Use of Graphene Oxide and Silica Fume in Cement-Based Composites. Materials 2021, 14, 6541. [CrossRef] [PubMed]

11. Allalou, S.; Kheribet, R.; Benmounah, A. Effects of calcined halloysite nano-clay on the mechanical properties and microstructure of low-clinker cement mortar. Case Stud. Constr. Mater. 2019, 10, e00213. [CrossRef]

12. Jura, J.; Ulewicz, M. Assessment of the Possibility of Using Fly Ash from Biomass Combustion for Concrete. Materials 2021, 14, 6708. [CrossRef]

13. Lisuzzo, L.; Cavallaro, G.; Milioto, S.; Lazzara, G. Halloysite nanotubes filled with MgO for paper reinforcement and deacidification. Appl. Clay Sci. 2021, 213, 106231. [CrossRef]

14. Wei Chong, B.; Othman, R.; Jaya, R.P.; Shu Ing, D.; Li, X.; Wan Ibrahim, M.H.; Abdullah, M.M.A.B.; Sandu, A.V.; Płoszaj, B.; Szmidla, J.; et al. Image Analysis of Surface Porosity Mortar Containing Processed Spent Bleaching Earth. Materials 2021, 14, 1658. [CrossRef]

15. Wei Chong, B.; Othman, R.; Sheng, T.W.; Ramadhansyah, P.J.; Abdullah, M.M.A.B. Properties of Mortar with Waste Tyre Rubber as Partial Sand Replacement. Key Eng. Mater. 2021, 879, 49-61.

16. Zahabizadeh, B.; Pereira, J.; Gonçalves, C.; Pereira, E.N.B.; Cunha, V.M.C.F. Influence of the printing direction and age on the mechanical properties of 3D printed concrete. Mater. Struct. 2021, 54, 25. [CrossRef]

17. Wolfs, R.J.M.; Bos, F.P.; Salet, T.A.M. Hardened properties of 3D printed concrete: The influence of process parameters on interlayer adhesion. Cem. Concr. Res. 2019, 119, 132-140. [CrossRef]

18. Rahul, A.V.; Santhanam, M.; Meena, H.; Ghani, Z. Mechanical characterization of 3D printable concrete. Constr. Build. Mater. 2019, 227, 116710. [CrossRef]

19. Sanjayan, J.G.; Nematollahi, B.; Xia, M.; Marchment, T. Effect of surface moisture on inter-layer strength of 3D printed concrete. Constr. Build. Mater. 2018, 172, 468-475. [CrossRef]

20. Panda, B.; Chandra Paul, S.; Jen Tan, M. Anisotropic mechanical performance of 3D printed fiber reinforced sustainable construction material. Mater. Lett. 2017, 209, 146-149. [CrossRef]

21. Zhang, Y.; Zhang, Y.; She, W.; Yang, L.; Liu, G.; Yang, Y. Rheological and harden properties of the high-thixotropy 3D printing concrete. Constr. Build. Mater. 2019, 201, 278-285. [CrossRef]

22. Le, T.T.; Austin, S.A.; Lim, S.; Buswell, R.A.; Law, R.; Gibb, A.G.F.; Thorpe, T. Hardened properties of high-performance printing concrete. Cem. Concr. Res. 2012, 42, 558-566. [CrossRef]

23. Kaszyńska, M.; Skibicki, S.; Hoffmann, M. 3D Concrete Printing for Sustainable Construction. Energies 2020, 13, 6351. [CrossRef]

24. Shakor, P.; Nejadi, S.; Sutjipto, S.; Paul, G.; Gowripalan, N. Effects of deposition velocity in the presence/absence of E6-glass fibre on extrusion-based 3D printed mortar. Addit. Manuf. 2020, 32, 101069. [CrossRef]

25. Khalil, N.; Aouad, G.; El Cheikh, K.; Rémond, S. Use of calcium sulfoaluminate cements for setting control of 3D-printing mortars. Constr. Build. Mater. 2017, 157, 382-391. [CrossRef]

26. Jianchao, Z.; Zhang, T.; Faried, M.; Wengang, C.; Shanableh, A.; Maalej, M.; Barakat, S.; Omar, M.; Al-Toubat, S.; Al-Ruzouq, R.; et al. 3D printing cement based ink, and it's application within the construction industry. MATEC Web Conf. 2017, 120, 2003. [CrossRef]

27. Nerella, V.N.; Krause, M.; Näther, M.; Mechtcherine, V. Studying printability of fresh concrete for formwork free Concrete on-site 3D Printing technology (CONPrint3D). In Proceedings of the 25th Conference on Rheology of Building Materials, Regensburg, Germany, 2-3 March 2016.

28. Paul, S.C.; Tay, Y.W.D.; Panda, B.; Tan, M.J. Fresh and hardened properties of 3D printable cementitious materials for building and construction. Arch. Civ. Mech. Eng. 2018, 18, 311-319. [CrossRef]

29. Wolfs, R.J.M.; Suiker, A.S.J. Structural failure during extrusion-based 3D printing processes. Int. J. Adv. Manuf. Technol. 2019, 104, 565-584. [CrossRef]

30. Perrot, A.; Rangeard, D.; Pierre, A. Structural built-up of cement-based materials used for 3D-printing extrusion techniques. Mater. Struct. 2016, 49, 1213-1220. [CrossRef]

31. Hoffmann, M.; Skibicki, S.; Pankratow, P.; Zieliński, A.; Pajor, M.; Techman, M. Automation in the Construction of a 3D-Printed Concrete Wall with the Use of a Lintel Gripper. Materials 2020, 13, 1800. [CrossRef] 
32. Kaszynska, M.; Hoffmann, M.; Skibicki, S.; Zielinski, A.; Techman, M.; Olczyk, N.; Wróblewski, T. Evaluation of suitability for 3D printing of high performance concretes. MATEC Web Conf. 2018, 163, 1002. [CrossRef]

33. Skibicki, S.; Pultorak, M.; Kaszynska, M. Evaluation of Material Modification using PET in 3D Concrete Printing Technology. IOP Conf. Ser. Mater. Sci. Eng. 2021, 1044, 12002. [CrossRef]

34. Ding, T.; Xiao, J.; Qin, F.; Duan, Z. Mechanical behavior of 3D printed mortar with recycled sand at early ages. Constr. Build. Mater. 2020, 248, 118654. [CrossRef]

35. Nguyen-Van, V.; Panda, B.; Zhang, G.; Nguyen-Xuan, H.; Tran, P. Digital design computing and modelling for 3-D concrete printing. Autom. Constr. 2021, 123, 103529. [CrossRef]

36. Panda, B.; Lim, J.H.; Tan, M.J. Mechanical properties and deformation behaviour of early age concrete in the context of digital construction. Compos. Part B Eng. 2019, 165, 563-571. [CrossRef]

37. Federowicz, K.; Techman, M.; Sanytsky, M.; Sikora, P. Modification of Lightweight Aggregate Concretes with Silica NanoparticlesA Review. Materials 2021, 14, 4242. [CrossRef]

38. van den Heever, M.; Bester, F.; Kruger, J.; van Zijl, G. Mechanical characterisation for numerical simulation of extrusion-based 3D concrete printing. J. Build. Eng. 2021, 44, 102944. [CrossRef]

39. Nematollahi, B.; Vijay, P.; Sanjayan, J.; Nazari, A.; Xia, M.; Naidu Nerella, V.; Mechtcherine, V. Effect of Polypropylene Fibre Addition on Properties of Geopolymers Made by 3D Printing for Digital Construction. Materials 2018, 11, 2352. [CrossRef]

40. Du, X.; Jin, L.; Ma, G. Macroscopic effective mechanical properties of porous dry concrete. Cem. Concr. Res. 2013, 44, 87-96. [CrossRef]

41. Wu, Y.-C.; Yang, Q.; Kong, X.; Zhi, P.; Xiao, J. Uncertainty quantification for the representative volume element of geometrically monoclinic 3D printed concrete. Int. J. Solids Struct. 2021, 226-227, 111102. [CrossRef]

42. Xiao, J.; Li, W.; Corr, D.J.; Shah, S.P. Simulation Study on the Stress Distribution in Modeled Recycled Aggregate Concrete under Uniaxial Compression. J. Mater. Civ. Eng. 2013, 25, 504-518. [CrossRef]

43. Kim, K.; Park, S.; Kim, W.; Jeong, Y.; Lee, J. Evaluation of Shear Strength of RC Beams with Multiple Interfaces Formed before Initial Setting Using 3D Printing Technology. Materials 2017, 10, 1349. [CrossRef]

44. Marchment, T.; Sanjayan, J.G.; Nematollahi, B.; Xia, M. Interlayer Strength of 3D Printed Concrete. In 3D Concrete Printing Technology; Sanjayan, J., Nazari, A., Nematollahi, B., Eds.; Elsevier: Amsterdam, The Netherlands, 2019; pp. 241-264, ISBN 9780128154816.

45. Panda, B.; Paul, S.C.; Mohamed, N.A.N.; Tay, Y.W.D.; Tan, M.J. Measurement of tensile bond strength of 3D printed geopolymer mortar. Measurement 2018, 113, 108-116. [CrossRef]

46. Zareiyan, B.; Khoshnevis, B. Effects of interlocking on interlayer adhesion and strength of structures in 3D printing of concrete. Autom. Constr. 2017, 83, 212-221. [CrossRef]

47. Feng, P.; Meng, X.; Chen, J.-F.; Ye, L. Mechanical properties of structures 3D printed with cementitious powders. Constr. Build. Mater. 2015, 93, 486-497. [CrossRef]

48. EN 12390-13:2014-02. Testing Hardened Concrete-Determination of Secant Modulus of Elasticity in Compression.

49. Kaszynska, M.; Olczyk, N.; Techman, M.; Skibicki, S.; Zielinski, A.; Filipowicz, K.; Wróblewski, T.; Hoffmann, M. Thermalhumidity parameters of 3D printed wall. IOP Mater. Sci. Eng. 2019, 471, 082018.

50. EN 1015-3:2000. Methods of Test for Mortar for Masonry_Part 3: Determination of Consistence of Fresh Mortar (by Flow Table).

51. Cho, S.; Kruger, J.; Bester, F.; van den Heever, M.; van Rooyen, A.; van Zijl, G. A Compendious Rheo-Mechanical Test for Printability Assessment of 3D Printable Concrete. In Proceedings of the Second RILEM International Conference on Concrete and Digital Fabrication; Bos, F.P., Lucas, S.S., Wolfs, R.J.M., Salet, T.A.M., Eds.; Springer International Publishing: Cham, Switzerland, 2020; pp. 196-205, ISBN 978-3-030-49916-7.

52. Casagrande, L.; Esposito, L.; Menna, C.; Asprone, D.; Auricchio, F. Effect of testing procedures on buildability properties of 3D-printable concrete. Constr. Build. Mater. 2020, 245, 118286. [CrossRef]

53. Chougan, M.; Ghaffar, S.H.; Sikora, P.; Chung, S.-Y.; Rucinska, T.; Stephan, D.; Albar, A.; Swash, M.R. Investigation of additive incorporation on rheological, microstructural and mechanical properties of 3D printable alkali-activated materials. Mater. Des. 2021, 202, 109574. [CrossRef]

54. Sikora, P.; Chung, S.-Y.; Liard, M.; Lootens, D.; Dorn, T.; Kamm, P.H.; Stephan, D.; Abd Elrahman, M. The effects of nanosilica on the fresh and hardened properties of 3D printable mortars. Constr. Build. Mater. 2021, 281, 122574. [CrossRef]

55. Roussel, N.; Lanos, C. Plastic Fluid Flow Parameters Identification Using a Simple Squeezing Test. Appl. Rheol. 2003, 13, 132-141. [CrossRef]

56. Toutou, Z.; Roussel, N.; Lanos, C. The squeezing test: A tool to identify firm cement-based material's rheological behaviour and evaluate their extrusion ability. Cem. Concr. Res. 2005, 35, 1891-1899. [CrossRef]

57. EN 12390-3:2019. Testing Hardened Concrete_Part 3: Compressive Strength of Test Specimens.

58. Duballet, R.; Baverel, O.; Dirrenberger, J. Classification of building systems for concrete 3D printing. Autom. Constr. 2017, 83, 247-258. [CrossRef]

59. Wolfs, R.J.M.; Bos, F.P.; Salet, T.A.M. Early age mechanical behaviour of 3D printed concrete: Numerical modelling and experimental testing. Cem. Concr. Res. 2018, 106, 103-116. [CrossRef] 
60. Wolfs, R.J.M.; Bos, F.P.; Salet, T.A.M. Triaxial compression testing on early age concrete for numerical analysis of 3D concrete printing. Cem. Concr. Compos. 2019, 104, 103344. [CrossRef]

61. Li, Z.; Hojati, M.; Wu, Z.; Piasente, J.; Ashrafi, N.; Duarte, J.P.; Nazarian, S.; Bilén, S.G.; Memari, A.M.; Radlińska, A. Fresh and Hardened Properties of Extrusion-Based 3D-Printed Cementitious Materials: A Review. Sustainability 2020, 12, 5628. [CrossRef]

62. EN 1992-1-1:2004 + A1:2014 Eurocode 2: Design of Concrete Structures. 